\title{
USING VISUAL REPRESENTATIONS AS AN ALTERNATIVE IN TEACHING SIMULTANEOUS EQUATIONS
}

\author{
NurNadhirah Haji Nordin ${ }^{1}$, KhairulAmilin Tengah ${ }^{2}$, Masitah Shahrill ${ }^{3}$, Abby Tan ${ }^{4}$ and \\ Elvynna Leong ${ }^{5}$ \\ ${ }^{1}$ Masin Secondary School, Ministry of Education,Brunei \\ ${ }^{2,3}$ Sultan HassanalBolkiah Institute of Education, Universiti Brunei Darussalam, Brunei \\ ${ }^{4,5}$ Faculty of Science, Universiti Brunei Darussalam, Brunei
}

\begin{abstract}
It is widely known that students normally struggle in the mathematics topic of algebra They tend to steer away from algebraic problems such as solving linear equation with one variable, let alone simultaneous equations, which require them to determine the values of two variables. This action research study investigates the effect of replacing the common symbolic representations with pictorial (static visual) representations in simultaneous equations lessons of 38 low-performing Year 10 students. The data for the study was collected by means of pre- and post-tests and facilitated by three worksheets as the intervention instruments. During the lessons, pictorial representations were used in solving simultaneous equations questions. These entailed drawing several pictorials that were given in the equations. In particular, drawings of burgers, fries, cheese slices, gift boxes and sweets were used as these were generally relatable to the students in real-life. The students were then provided with fresh worksheets and subsequently translated their workings from the pictorial part to $x$ and $y$. And thus forms the symbolic part of the intervention. From the students' pre-test and posttest scores, it was evident that the pictorial representations helped the students in making significant improvements in the topic.
\end{abstract}

Keywords: Algebra, Simultaneous Equations, Pictorial Representation, Mathematics Performance

\section{Introduction}

Mathematics has a high relevance and practical applications in real life forming a base for all technological and scientific studies (Mundia, 2010; Chong and Shahrill, 2016; Fintiet al., 2016; Huda et al., 2017). Despite its importance, students tend to perform poorly in it. It is also widely known that algebra is one mathematics topic that students tend to struggle in (Samo, 2008). According to Devlin, algebra is not "arithmetic with letters" (Devlin, 2011). At the school level, he mentioned that arithmetic and algebra are two different forms of thinking about numerical issues. Many people find arithmetic hard, but the basic building block of the subject, which are numbers, exist naturally around us and this makes it possible to learn about arithmetic. This includes counting and measuring things or checking the baseball scores.

Algebra, on the other hand, is one more step removed from everyday world (Devlin, 2011). He further added that the $x$ and $y$ dealt with in algebra represent numbers in general, but not particular numbers and the human brain is not naturally appropriate to think at that level of abstraction. To be able to do so requires effort and training. Devlin also pressed on the fact that algebraic thinking is different that arithmetical thinking. This transition between the two may be difficult for some students, as they need to make some adjustments (Kilpatrick et al., 2001). There is then a need to help support the development of this thinking so that students make a smooth transition and so that they develop an appreciation of exploiting algebraic tactics to solve different problems (Caiet al., 2005).

Corresponding Author: Masitah binti Shahrill/ masitah.shahrill@ubd.edu.bn 
A study by Yahya and Shahrill (2015) on ten Year 11 repeaters sought to understand students' strategies in solving algebraic problems. It concentrated on strategies or approaches to three sub-topic on algebra: changing the subject of a given formula, factorisation of quadratic expressions and solving quadratic equations using quadratic formula. The results disclosed that most of the participants only acquired instrumental understanding as opposed to relational relationships in their algebra lessons. When required to change the subject of a given formula, the students used the changing of operation method, which is commonly used in Mathematics lessons in Brunei. The concept behind this method is balancing an equation. Results from this study show that the students were confused with the changes in the sign when using the said method. This is also a possible mistake that can lead students to wrong values of unknown variables in simultaneous equations.

Simultaneous equations are a set of two or more equations, with two or more unknown variables (Yunuset al., 2016). In the Bruneian school context, usually the students are expected to solve a system of simultaneous equations involving two linear equations and two unknown variables. The common methods of solving simultaneous equations problems are by using substitution or elimination. Solving simultaneous equations, which is of algebraic nature, requires the students to be able to manipulate and solve basic algebraic equations. In the substitution approach, the students have to make one of the variables the subject of one of the equations before they can perform substitution on the other equation and thus determine the value of the other unknown variable. For example, the students may be given a set of simultaneous equations $2 x+2 y=6$ and $x+2 y=4$. A possible approach to this question is by making $x$ the subject of the first equation, and subsequently substituting this formula for $x$ in the following equation to solve for $y$. The students need to perform the steps correctly without getting confused with the signs in order to evaluate the correct values of the two unknown variables.According to Samo (2008) and Chua et al. (2016), algebra uses symbols to generalise mathematics. These symbols may carry different meanings and interpretations in different situations, and students have various perceptions about these letters, symbols and signs. Findings from these studies revealed that students have many misconceptions in the use of symbols in Algebra, and this affected their learning of the topic.

The mathematics curriculum needs to be presented through multiple representations so that teaching is for mathematical understanding (Cope, 2015). These include physical (concrete), pictorial (static visual) and virtual (dynamic electronic) representations. Mathematics educators can use such representations or manipulatives in addition to the symbolic or abstract content to model the mathematics concepts. Cope cited that the first formal use of manipulatives in mathematics education happened in the late 1800s and that traditionally, mathematics educators and learners used concrete manipulatives, but many modern day classrooms make use of pictorial and virtual manipulatives.

This present study concentrated on using pictorial (static visual) representation to replace the usual $x$ and $y$ symbols to represent the unknowns. A pictorial manipulative, according to Cope (2015), is a stationary model that helps students visualize mathematical concepts. In the recent years, there have been numerous studies that experiment with steering away from the normal 'chalk and board' and symbol-oriented algebraic lessons using multiple representations. However, teachers need to be careful when choosing representatives; minimise the use of manipulatives that are common to the students outside school, such as toys to not make the students think of the activity as simple play (McNeil and Jarvin, 2007). McNeil and Jarvin also proposed that teachers take time to build the connection between the informal and formal understandings. Furthermore, students' preference of representations mostly depends on what they were taught in class, so teachers must be alert of the representations that can assist student learning (Ahmad et al., 2010).

In regards to representing algebra, comments made by teachers in a study conducted by Stylianou (2010) revealed that they view representation as an additional format, often visual and informal, of mathematics concepts at hand, which are symbolic notations. They also feel that certain representation, most notably numeric or symbolic, is more significant to the learning and doing mathematics while graphic and visual representations 
are secondary. The teachers also expressed that having to teach multiple representations to the students would add burden to their already overloaded curriculum and one teacher went on commenting "If we're to go into such steps for every problem, we would never, ever have time to complete the curriculum" (Stylianou, 2010, p. 337).

There are other studies that favour the use of visual representations. For example, a study carried out by MoyerPackenhamet al. (2012) on 19 low-achieving third-grade student. The study revolved around fractions, and was carried out over the time frame of three weeks. The students were divided into two groups: one group used Static Pictorial Models (SPM), while the other group used Dynamic Virtual Manipulation (DVM). Both groups had the same daily objectives. All the students in both groups made significant improvement after the intervention, with both groups performing equally well on the post-test questions with pictorial representations.

In another study by Suh and Moyer (2007), the use pictorials also showed positive results after their intervention. In the study that focused on algebraic relationships, the participants: 36 third-grade students were engaged with different algebraic representations (pictorial, symbolic and word problems). They were encouraged to use informal strategies to represent their relational thinking. The students were divided into two groups, placed in two different learning environments. Group One worked with the Virtual Balance Scale applet, and Group Two worked with a physical manipulative called Hands-On Equations. The students were required to solve simple linear equations using the two manipulatives. From the post-test, it was analysed that some students used pictures or drawings to aid them in solving the symbolic parts of the test. So from here it can be concluded that in some sense, exposing the students with alternative representations other than symbolic representations can help them in their learning.

\section{Methodology}

This study aims to find an alternative teaching approach, which will help enhance low-performing Year 10 students' performance. In this study, the students focus on using visual representations, in particular pictorials (static visual) such as shapes or drawings in place of symbols (to represent the unknown variables) to solve simultaneous equations. The simultaneous equations involve two equations and two unknown variables of linear nature.

This study is an action research that employs the use of both quantitative and qualitative methods to collect the necessary data. Action research is a popular choice because of the freedom that the practitioners have in controlling their own practices (McNiff and Whitehead, 2010). This study consists of a pre-test at the beginning, followed by several lessons of intervention where pictorial representations are used and later the students wrote a post-test.

\section{Sample}

The sample for this study is made up of 38 female students from two Year 10 classes, in one of the all-girls secondary schools in Brunei. The school is located about $40 \mathrm{~km}$ from the capital city, Bandar Seri Begawan. The same Mathematics teacher, who is also the first author, taught both the classes. The students were on the 5-year secondary level programme, doing normal General Certificate of Education 'O' Level Mathematics Syllabus ' $\mathrm{D}$ ', as opposed to the International General Certificate of Secondary Education Mathematics. The students do not have Additional Mathematics background and categorised as low-performing students with low to average command of mathematical skills. 


\section{Instruments}

The testing instrument used to measure the difference in students' performance was a set of six simultaneous equation questions administered to the students as both the pre-test and the post-test. The questions, each carrying three marks, are of symbolic nature, using the symbols $x$ and $y$ which the students are familiar with. The maximum mark possible for both the pre-test and post-test is 18 marks.

Prior to the intervention, while marking the pre-test papers, it appeared that majority of the students were struggling with solving algebraic equations of one variable. Possessing such skill is very important in solving simultaneous equations and thus, one 22-item worksheet on balancing algebraic equations was prepared. There were 10 pictorial questions and the remaining questions are of symbolic nature and a total of two periods were allocated to strengthen the students' foundation before moving further into the intervention. The worksheet is adapted from the pictorial section of an activity sheet from Suh and Moyer (2007). In their research, virtual and physical algebraic balances were used to develop third-grade students' representational fluency.

During the intervention, two sets of worksheets were used where the symbolic representation is replaced. Each worksheet consists of simultaneous equations questions of pictorial nature. The worksheets were prepared such that that the students are supposed to find the price of food items (burgers, fries and cheese slices) or the number of sweets in different gift boxes (round and square boxes). The testing instrument was tested for reliability in SPSS Version 21, returning a result of Cronbach Alpha $\alpha=0.765$. The test papers and worksheets were tested for validity with two experienced mathematics teachers in the school, which included the Head of the Mathematics department of the school. Throughout the intervention, a video recorder was used.

\section{Data Collection}

The data collection for the research started with a pre-test, administered to all 38 students in the sample. The students were given 20 minutes to complete the test individually. The pre-test papers were then marked and kept for future uses. It is clear that students were still struggling with solving algebraic equations of one variable. For example in the first question of the pre-test, the students were given the set of equations $2 y=6$ and $y+3 x=$ 9. A common mistake done by the students was manipulating the first equation to give them $y=6-4$, and the second equation to give them $y+x=\frac{9}{3}$. This shows that majority of the students were unable to fully grasp the concept of solving algebraic equations using the change of operations method. The students are used to thinking that they need to move the terms around, not knowing that the concept behind the move is actually balancing both sides of the equation. Since being able to solve such questions is vital in any algebraic topic, a worksheet on using balancing to solve such algebraic questions was then prepared. This was done over two periods (50 minutes): first introduced was an equation as a balance and asking the students what would happen if one 'item' is taken from one side of the balance but not from the other side. The students were further questioned of how they were to prevent the balance from collapsing if they take certain 'item' from one side of the balance or add a certain 'item' to one side of the balance.

The intervention followed after, and stretched over the time period of two weeks. The intervention, running along lesson plans prepared by the first author was divided into two parts: the pictorial part and the symbolic part. The two worksheets were used in both parts. In the first part, the students solved together with the teacher who is also the first author, the simultaneous equations by using pictorials. This means that they drew out whatever pictorials that were given in the equations. In particular, drawings of burgers, fries, cheese slices, gift boxes and sweets were used as these are not gender-biased and generally all the students can relate to these items. After the two worksheets were worked through, the students were provided with fresh worksheets and together with the teacher they translated their working from the pictorial part to $x$ and $y$. This is the symbolic part of the intervention. The pictorial part took a significantly longer time as drawing the pictorials take time. 
For both worksheets, the students were given some time to approach the questions and later the teacher discussed the solutions. At the end of the intervention, the students sat for a post-test and were given 20 minutes to do so. The post-test was then marked analysed.

\section{Data Analysis}

Both the pre-test and post-test were marked such that the students can score two marks for getting one correct answer (either $x$ or $y$ ) with supporting working or both correct answers without working. The remaining one mark is awarded for employing the correct method (substitution) to solve the question. The pre-test and post-test scores were keyed in to SPSS Version 21 software. A paired samples $t$-test with significance level $95 \%$ is appropriate, as this research wants to find if there is a significant difference between the pre-test and post-test scores of the sample. In order for a paired samples $t$-test to be used, four assumptions are to be met (Lund and Lund, 2013):

1. the dependent variable is continuous;

2. the independent variable consists of two categorical groups and the same subjects are present in the same group ("related" group);

3. there should be no significant outliers in the differences between the two groups; and

4. the distribution of the differences of the dependent variable in the two related groups are approximately normally distributed.

If any of these assumptions are not met, the alternative for a paired samples $t$-test, which is the nonparametric Wilcoxon Signed-Rank test will then be used.

\section{Results}

The data for the research question 'How does using visual representation, in particular static pictorial in solving simultaneous equations affect students' performance on the topic?' was collected by using means of pre-test and post-test. The same test paper was used as both the pre-test and post-test and the maximum possible mark is 18 marks.

Table 1Descriptive statistics of pre-test and post-test scores

\begin{tabular}{lccccc}
\hline & Range & Minimum & Maximum & Mean(M) & Std. Deviation(SD) \\
\hline Pre-test Score & 16.00 & 0.00 & 16.00 & 3.6053 & 4.01039 \\
Post-test Score & 16.00 & 0.00 & 16.00 & 7.6053 & 5.28404
\end{tabular}

From Table 1, it is clear that students' performance improve after intervention. Notably, the number of failures also decreases. However, four students did not improve after intervention. The scores of three students remained stagnant. The descriptive statistics for the difference are presented in Table 2 below. The range is between -4 to 14 out of 18 marks, and on average each student improved by 4.00 marks as shown by the mean $M$.

Table 2Descriptive statistics for the difference between pre-test and post-test scores

\begin{tabular}{cccccc}
\hline & Range & Minimum & Maximum & Mean (M) & Std. Deviation (SD) \\
\hline Post-test - Pre-test Score & 18.00 & -4.00 & 14.00 & 4.0000 & 4.55002 \\
\hline
\end{tabular}

However, the fourth assumption is not met for the paired t-test. When a normality test was run to the difference between the pre-test and post-test, the significance of the test is less than 0.05 , indicating that the difference between the two tests deviates away from the normal distribution (Table 3). 
NurNadhirah Haji Nordin, KhairulAmilin Tengah, MasitahShahrill, Abby Tan and Elvynna Leong/ Using Visual Representations as an Alternative in Teaching Simultaneous Equations

Table 3Normality test for pre-test and post-test scores

\begin{tabular}{lccc}
\hline & \multicolumn{3}{c}{ Saphiro-Wilk } \\
\cline { 2 - 4 } & Statistic & df & Sig. \\
\hline Difference & 0.934 & 38 & 0.027 \\
\hline
\end{tabular}

Hence a paired samples $t$-test will not be appropriate to test if the improvement is significant. This is anticipated due to the small sample size. Hence, a Wilcoxon Signed-Rank test was run on the SPSS. If the significance level of the test is below 0.05 ( $p$-value $<0.05$ ), this means that the hypothesis is accepted and if the significance level is above 0.05 ( $p$-value $>0.05$ ), this indicates that the hypothesis is rejected.

Table 4 Wilcoxon Signed-Rank Test for the difference between pre-test and post-test scores

\begin{tabular}{lc}
\hline & Post-test Score - Pre-test Score \\
\hline$Z$ & -4.302 \\
Asymp. Sig. (2-tailed) & 0.000 \\
\hline
\end{tabular}

The results in Table 4 shows that the z-value is -4.302 and the asymptotic significance is 0.000 , which is less than 0.05 ( $p$-value < 0.05 ). This means that the hypothesis is accepted: there is indeed a significant difference between the pre-test $(M=3.605, \mathrm{SD}=4.010)$ and the post-test $(M=7.605, \mathrm{SD}=5.284)$, implying that the improvement is significant.

\section{Discussion}

The data from the pre-test and post-test scores indicate that there is indeed a difference between the mean scores of the two, with the mean of post-test being higher than that of the pre-test, indicating an improvement. When a Wilcoxon Signed-Rank test was run on SPSS, the improvement is significant. This implies that the incorporation of pictorial representation in place of the usual symbolic representation in the simultaneous equations lesson has affected the students' performance in a positive way. Majority of the students improved significantly after the intervention. This finding is consistent with the findings of the case studies by MoyerPackenhamet al. (2012) and Suh and Moyer (2007), whereby the results of the students in their sample improved significantly after the researchers integrated pictorial representations in their lessons on fraction, algebraic relationship and geometry respectively. Findings from this study can thus add on to the list of mathematical topics that can be approached by using pictorial representations to help improve students' performance.

\section{Conclusions}

The findings show that there is a significant difference between the pre-test and post-test scores of the students. It can be concluded that pictorial representations in place of symbolic representations during simultaneous equations lessons has improved the performance of majority of the students. The failure rate in the pre-test (81.6\%) has decreased to $55.3 \%$ in the post-test. On average, each student improved by 4 marks out of 18 . This finding is consistent with previous studies that support the use of multiple representations in Mathematics lessons, such as by McNeil and Jarvin (2007), Stylianou (2010), Ahmad et al. (2010) and Cope (2015).

This present study had a small sample size and is limited to only low-performing Year 10 students. Moreover, the research was carried out in an all-girls school thus the findings can be gender-biased. The findings might be significantly or slightly different when the study was carried out in a co-ed or all-boys school. This is because gender differences still occur, although lessening (McCoy, 2005). For the research, specifically the substitution and pictorial representations were used during the intervention. There are however, other methods available 
such as elimination, andseveral other types of representations, such as virtual and concrete representations that are available and can be used during the intervention.

\section{References}

Ahmad, A., Ahmad Tarmizi, R., andNawawi, M., 2010, Visual representations in mathematical word problem solving among form four students in Malacca. Procedia Social and Behavioral Sciences, 8, 356-361.

Cai, J., Lew, H. C., Morris, A., Moyer, J. C., Ng, S. F., andSchmittau, J., 2005, The development of student's algebraic thinking in earlier grades: a cross-cultural comparative perspective.ZentralblattFürDidaktik Der Mathematik, 37(1), 5-15.

Chong, M. S. F., and Shahrill, M., 2016, The use of an emerging framework to explore students' cognitive competency. Indian Journal of Science and Technology, 9(16). doi:10.17485/ijst/2016/v9i16/78812.

Chua, G. L. L., Shahrill, M., and Tan, A., 2016, Common misconceptions of algebraic problems: identifying trends and proposing possible remedial measures. Advanced Science Letters, 22(5/6), 1547-1550.

Cope, L., 2015, Math manipulatives: making the abstract tangible. Delta Journal of Education, 5(1), 10-19.

Devlin, K., 2011,What is Algebra? Date of access: 21/10/2016. https://profkeithdevlin.org/2011/11/20/what-isalgebra/

Finti, H. N. F. M. M., Shahrill, M., and Salleh, S. M., 2016, Integrating virtual manipulative with the use of iPad in the teaching and learning of fractions. Knowledge Management \& E-Learning, 8(4), 581-601.

Huda, M., Hehsan, A., Jasmi, K. A., Mustari, M. I., Shahrill, M., Basiron, B., and Gassama, S. K., 2017, Empowering children with adaptive technology skills: careful engagement in the digital information age. International Electronic Journal of Elementary Education, 9(3) 693-708.

Kilpatrick, J., Swafford, J., andFindell, B., 2001, Adding it up: helping children learn mathematics (Washington, DC: National Academy Press).

Lund, A. and Lund, M., 2013, Dependent t-test using SPSS Statistics. Date of access 21/08/2016. https://statistics.laerd.com/spss-tutorials/dependent-t-test-using-spss-statistics.php

McCoy, L., 2005, Effect of demographic and personal variables on achievement in eighth-grade algebra. The Journal of Educational Research, 98, 131-135.

McNeil, N., and Jarvin, L., 2007, When theories don't add up: disentangling the manipulatives debate. Theory into Practice, 46(4), 309-316.

McNiff, J., and Whitehead, J., 2010,You and Your Action Research Project ( $3^{\text {rd }}$ ed.) (Abingdon: Routledge).

Moyer-Packenham, P., Ulmer, L., and Anderson, K., 2012, Examining pictorial models and virtual manipulatives for third-grade fraction instruction. Journal of Interactive Online Learning, 11(3), 103-113.

Mundia, L., 2010, Problems in learning mathematics: comparison of Brunei junior high school students in classes with and without repeaters. Journal of Mathematics Research, 2, 150-160.

Samo, M., 2008, Students' perceptions about the symbols, letters and signs in algebra and how do these affect their learning of algebra: A case study in a government girls secondary school, Karachi, Pakistan. The Aga Khan University, Karachi, Pakistan: M.Ed dissertation.

Stylianou, D. A., 2010, Teachers' conceptions of representation in middle school mathematics. Journal of Mathematics Teacher Education, 13(4), 325-343.

Suh, J., and Moyer, P., 2007, Developing students' representational fluency using virtual and physical algebra balances. Journal of Computers in Mathematics and Science Teaching, 26(2), 155-173.

Yahya, N., andShahrill, M., 2015,The strategies used in solving algebra by secondary school repeating students. Procedia- Social and Behavorial Sciences, 186, 1192-1200.

Yunus, D. H. R. P. H., Shahrill, M., Abdullah, N. A., and Tan, A., 2016, Teaching by telling: Investigating the teaching and learning of solving simultaneous linear equations. Advanced Science Letters, 22(5/6), 1551-1555. 